\title{
INCIDENCE OF STRESS FRACTURE IN MILITARY RECRUITS: DOES MODIFICATION OF TRAINING PROGRAMME REDUCE THE INCIDENCE?
}

\section{Dr PMP Singh*}

\section{Dr Hrishikesh}

Pande

\section{ABSTRACT}

Introduction: Stress fracture though easily preventable is often neglected.

Objectives: 1 . To assess whether modification of the training programme reduces the incidence of stress fracture among recruits.

Results: The average incidence of stress fracture from 01 Jul 2000 to 30 Jun 2004 was 36.10 per 1000, while after modification of the training programme it was 24.96 per 1000 . This reduction in incidence of stress fracture was found to be statistically significant. Chi square value is 17.87, $(\mathrm{p}<0.001)$

Discussion: Several studies on prevention of stress fractures in basic military training have been conducted. Incidence of stress fracture may be reduced by modification of training schedules.

Limitations: Due to various constraints, the modified training programme could be implemented only for one year.

What we already know?

1. The incidence of stress fracture and various modalities of reduction in incidence of stress fracture in military recruits are known in military recruits

What this article adds?

1. This article add a novel method of reduction in incidence of stress fracture in military recruits.

\section{KEYWORDS : Training, Stress Fracture , Incidence, Prevention, Battle Physical Efficiency Test}

\section{INTRODUCTION}

Abnormal and repetitive loading on normal bone leads to microdamage and then fracture. They usually occur after sudden increase in physical activity. ${ }^{1,2}$

Stress reaction in bone, which may proceed to a fracture, is a significant problem in military recruits and in athletes , particularly long distance runners. Stress fractures cause considerable interference to training and competition. These skeletal overuse injuries are the result of the failure of bone to successfully adapt to the repetitive loads encountered during running. As more young athletes are training and competing in sports, physicians will likely see more stress fractures among the young. A recent study of track athletes showed an incidence of stress fractures of $20 \%{ }^{3,4}$ Due to the abrupt and rigorous nature of basic training, the military recruit population is at particular risk of stress fracture.

High incidence of stress fracture has always been the Achille's heel of every training establishment. This condition though easily prevented by following few simple preventive measures is often neglected.Moreover stress fracture is often the cause of invalidment of a number of recruits during the early stages of their training career. It was keeping in view the importance of the high incidence of stress fracture in the training centers that the present study was carried out.

\section{AIM}

To study the incidence of stress fracture among recruits undergoing training in a training center.

\section{OBJECTIVES}

1. To assess whether modification of the training progr amme reduces the incidence of stress fracture among recruits.

2. To give suitable recommendations for reduction of the incidence of stress fracture among recruits undergoing training in training centers.

\section{MATERIALS AND METHODS}

Study Design : The study design was a retrospective cohort study.

Sampling Procedure : The entire population of recruits who were undergoing training in the training centre during the period of study were included in the study.

METHODOLOGY : The Hospital admission record of the training center was scrutinised for cases of stress fracture admitted to the local military hospital for four years from Jul 2000 to Jul 2004 . Subsequently the data was validated from the admission and discharge register of the local military hospital. During their two year training the recruits were having a BPET (Battle Physical Efficiency Test) once a month. The BPET test includes a rigorous $5 \mathrm{~km}$ run, jumping across a 9 foot ditch and various other strenuous physical activities which are required to be completed within a given time frame. As per training schedule which was being followed a number of BPETs were held for the recruits at the time of their final test before completion of their training. This included BPETs conducted at Squad, Battery, Regiment and Commandant level. These BPETs at the time of their final test were being held within a time frame of 15 days to one month. Subsequently the training programme was modified and implemented strictly in consultation with the administrative authorities. All other parameters such as dietary scale and shoes of the recruits were kept constant during the period of the study. The study period was for two training sessions from Jul 2004 to Jul 2005. The modification was that instead of having a number of BPETs at various levels only one single BPET was conducted viz at Commandant level. Thereafter the incidence of stress fracture was again observed as before.. Since the training of these recruits was for a period of two years, there was a substantial overlap between the study population of recruits from Jul 2000 to Jun 2004 and from Jul 2004 to Jun 2005.

Sociodemographic Profile Of The Study Population: Most of the recruits were from rural background, belonging to poor socioeconomic status. Their nutritional status at the time of 
reporting for training was also similar; and a significant number of them tend to be slightly underweight.

\section{Case Definition Of A Case Of Stress Fracture}

Cases presenting with features of mechanical pain, focused pain and/or swelling were diagnosed as stress fracture and confirmed by X Ray of the affected part. ${ }^{1}$

\section{RESULTS}

The number of cases of stress fracture which occurred during four years from Jul 2000 to Jul 2004 is tabulated in Table 1.

The mean number of cases of stress fracture which occurred during the four years from Jul 2000 to Jul 2004 was 229.25 cases per year. The mean strength of recruits in the training center during these four years was 6348.75 . Thus the mean incidence of stress fracture during this period was 36.10 per 1000 . The mean plus minus two standard deviation gives a range of incidence from 41.34 per 1000 to 30.85 per 1000 . The incidence of stress fracture among the recruits subsequent to implementation of the modified training programme is tabulated in table 2 .

The reduction in incidence of stress fracture was thus statistically significant as the incidence of stress fracture from $01 \mathrm{Jul} 2004$ to 30 Jun 2005 is below the mean minus two standard deviation of the average incidence of stress fracture for four years from 01 Jul 2000 to 30 Jun 2004 . Chi square value is 17.87, $(\mathrm{p}<0.001)$

\section{DISCUSSION}

Stress fracture which is a common overuse injury in athletes and military recruits was first reported by Breithaupt in $1855 .{ }^{6}$

Stress fractures of the ankle and foot are a major cause of disability in athletes. The incidence of stress fractures in the general athlete population is less than one percent. However, in runners, the incidence may be as high as fifteen percent. ${ }^{5}$ Joseph J Knapik, Katy Reynolds and Kyle L Hoedebecke reported an overall incidence of stress fracture of 3 per thousand in active duty service members; and a much higher incidence of 19 per thousand for male and 80 per thousand for female Army basic trainees.?

SC Singh and A Banerjee reported 37 cases of stress fracture in a population of 1014 gentleman cadets. ${ }^{8}$ Abhinav Bhatnagar, Manoj Kumar, Deepak Shivanna, Aski Bahubali and , Dayanand Manjunath reported an incidence of stress fracture of $15 \%$ among 2000 BSF recruits. ${ }^{9}$

As a consequence of increasing participation of young athletes in training and competing in sports, physicians are likely to see more stress fractures in the young population. Daniel K. Ostlie, and Stephen M. Simons, reported an incidence of stress fractures of twenty percent. Tarsal navicular stress fractures, though uncommon, were reported by them as important causes of foot pain in athletes..$^{10}$ This incidence is far higher than the incidence of stress fracture observed in the present study.

Daniel and Ostlie were the pioneers in reporting tarsal navicular fractures in 1970 . Training errors, overuse and vigorous weight bearing activities are reported to be the common predisposing factors leading to tarsal navicular stress fractures. ${ }^{10}$

Increased training volume or intensity as a risk factor for stress fracture was proposed by Stefanos F Haddad . ${ }^{6}$ Stuart J Warden, Irene S Davis, and Michael Fredericson reported that individuals who were exposed to large changes in physical activity had an increased risk of Bone Stress Injury. ${ }^{11}$
Keith Rome, Helen HG Handoll and Robert L Ashford observed that use of footwear with shock absorbing inserts leads to lower incidence of stress fractures in military personnel.

Despite various methods having been proposed to prevent stress fractures relatively few have been validated by studies of appropriate magnitude to justify definitive recommendations. Several studies on prevention of stress fractures in basic military training have been conducted. However, their usefulness in other populations is unknown. ${ }^{12}$

Incidence of stress fracture may be reduced by modification of training schedules. Specific training regimens may need individualization. Stretching of leg muscles during warm up had no significant effect in prevention of stress fracture. ${ }^{12}$

Various workers have also proposed reducing the loads applied to the skeleton, as a modality of prevention of stress fracture. These techniques may include, instructing an athlete to "run softer" or with a higher stride rate, which helps to reduce impact-related forces; or increase the strength and/or endurance of local musculature. ${ }^{11}$ Addressing training errors as the athlete returns to sports participation; and education of the athlete, coach, and trainer also continue to be important and challenging aspects in prevention of stress fracture.$^{2,6,13,14}$ Ekenman I, Milgrom C, Finestone A, Begin M, Olin C, Arndt T et al observed that biomechanical orthoses led to a lower incidence of stress fracture in infantry recruits. ${ }^{13}$ Karl B. Fields, Jeannie C. Sykes, Katherine M. Walker, and Jonathan C. Jackson observed that fewer injuries resulted when there was a reduction in a 12 weeks basic training program. ${ }^{15}$

Several workers have reported use of appropriate orthotics, such as shock-absorbing shoe inserts, as effective in reducing the incidence of lower limb stress fractures in military recruits. ${ }^{9}$ Though the mechanism of action of various foot orthotics is debatable, they have been in use since over 50 years. ${ }^{15}$ Though the data are controversial, calcium and vitamin D supplement ation may also help to prevent stress fracture. ${ }^{12}$

Despite extensive search on medline, and various medical related web sites on the internet no similar studies were found. The key words used for searching were "Training, Stress Fracture, Incidence". Apparently there were no studies similar to our study as regards modification of training schedule significantly reducing the incidence of stress fracture in military recruits. Moreover there was no Indian study among those few studies found published as regards reduction of incidence of stress fracture.

Clinical evaluation of healing, rehabilitation, and gradual resumption of activities can improve the chances of a favorable outcome for this challenging problem.

\section{Limitations}

A major limitation of this study was that due to various constraints, the modified training programme could be implemented only for one year. Implementing the modified training programme and follow up of the recruits for the incidence of stress fracture for a longer period would have been more fruitful.

\section{Conclusion And Recommendations}

Keeping in view the importance of stress fracture in every training establishment and stress fracture often being the cause of invalidment of a number of recruits during the early stages of their training career the workers propose a few recommendations. Due thought should be given to the rigorous training schedule to which the recruits are subjected during their training in the training centers. The 
training programme be suitably modified after consulting the medical authorities. Implementation of the modified training programme should then be strictly monitored by both the medical authorities and the administrative authorities.$^{12}$ The workers also recommend that suitable dietary modifications be carried out in training centres . Vegetarians are authorized additional milk. However many a times the milk is used up in the form of tea or kheer thus depriving the vegetarians of their share of milk calcium. Eggs being a relatively better source of calcium, it is strongly recommended that vegetarians be educated or motivated to become egg vegetarians. The additional of dietary calcium will also help in further reducing the incidence of stress fracture in training centers. $^{16}$

Keeping in view the lack of such studies, it is strongly recommended that more such studies be carried out with respect to both training schedule as well as dietary modifications in various training centers. Conducting more such studies will help in validating the results obtained by the present study. The recommendations if implemented will go long way in reducing the incidence of stress fracture in recruits in the Armed Forces of our country. The treatment of stress fracture is time consuming. It depends on the risk of potential complications that may occur depending on the site of the fracture. On account of this, the treatment of stress fractures is time consuming. Hence, prevention of stress fractures is of key importance and requires a multidisciplinary approach. ${ }^{17}$

Table 1: Incidence of stress fracture among recruits during four years from 01 Jul 2000 to 30 Jun 2004

\begin{tabular}{|c|c|c|c|c|c|}
\hline \multirow[t]{2}{*}{$\begin{array}{l}\text { Serial } \\
\text { number }\end{array}$} & \multicolumn{2}{|c|}{$\begin{array}{l}\text { Training } \\
\text { session }\end{array}$} & \multirow{2}{*}{$\begin{array}{l}\text { Number of } \\
\text { cases of } \\
\text { stress } \\
\text { fracture }\end{array}$} & \multirow[t]{2}{*}{$\begin{array}{l}\text { Strength } \\
\text { of recruits }\end{array}$} & \multirow[t]{2}{*}{$\begin{array}{l}\text { Incidence } \\
\text { (Per 1000) }\end{array}$} \\
\hline & From & To & & & \\
\hline 1. & $\begin{array}{l}01 \mathrm{Jul} \\
2000\end{array}$ & \begin{tabular}{|l}
30 Jun \\
2001
\end{tabular} & 215 & 6144 & 34.99 \\
\hline 2. & \begin{tabular}{|l|}
$01 \mathrm{Jul}$ \\
2001
\end{tabular} & $\begin{array}{l}30 \text { Jun } \\
2002\end{array}$ & 193 & 5643 & 34.20 \\
\hline 3. & $\begin{array}{l}01 \mathrm{Jul} \\
2002\end{array}$ & $\begin{array}{l}30 \text { Jun } \\
2003\end{array}$ & 194 & 5775 & 33.59 \\
\hline 4. & $\begin{array}{l}01 \mathrm{Jul} \\
2003\end{array}$ & \begin{tabular}{|l|}
30 Jun \\
2004
\end{tabular} & 315 & 7833 & 40.21 \\
\hline 4. & Total & & 917 & 25395 & 36.10 \\
\hline
\end{tabular}

Table 2: Incidence of stress fracture among recruits from 01 Jul 2004 to 30 Jun 2005

\begin{tabular}{|l|l|l|l|l|l|}
\hline $\begin{array}{l}\text { Serial } \\
\text { number }\end{array}$ & Training session & $\begin{array}{l}\text { Number of } \\
\text { fases of } \\
\text { stress } \\
\text { fracture }\end{array}$ & $\begin{array}{l}\text { Strength } \\
\text { of } \\
\text { recruits }\end{array}$ & $\begin{array}{l}\text { Incidence } \\
\text { (Per 1000) }\end{array}$ \\
\hline 1. & $\begin{array}{l}\text { 01 Jul } \\
2004\end{array}$ & $\begin{array}{l}\text { 30 Jun } \\
\text { 2005 }\end{array}$ & 165 & 6609 & 24.96 \\
\hline
\end{tabular}

\section{REFERENCES}

1. Saunier J, Chapurlat R. Stress fracture in athletes. Joint Bone Spine. 2018 May;85(3):307-310. doi: 10.1016/j.jbspin.2017.04.013. Epub 2017 May 13.

2. Patrick Graham. Tibial Stress Fracture in a Runner. Orthopaedic Nursing : November/December 2018-Vol 37, Issue 6, 382-384.

3. K Rome, Helen HG Handoll, Robert L Ashford. Interventions for preventing and treating stress fractures and stress reactions of bone of the lower limbs in young adults. Cochrane Rev Abstract. 2005; The Cochrane Collaboration. Art. No.: CD000450. DOI: 10.1002/14651858.CD000450.pub2.

4. Kim Bennell, Kay Crossley, Jyotsna Jayarajan, Elizabeth Walton, Z Stephen Kiss, Tim Wrigley, Ground Reaction Forces and Bone Parameters in Females With Tibial Stress Fracture. Med Sci Sports Exerc 36 (3) : 397-404 , 2004. DOI: 10.1249/01.MSS.0000117116.90297.E1

5. Michael C. Greaser. Foot and Ankle Stress Fractures in Athletes. Orthop Clin N Am 47 (2016) 809-822 . http://dx.doi.org/10/1016/j.ocl.2016.05.016.

6. Stefanos F Haddad. Stress Fractures. Updated: Mar 09, 2020. Available from : URL https://emedicine.medscape.com/article/1270244-overview\#showall. [11 screens]. Accessed 22 Jun 2020.

7. Joseph J Knapik, Katy Reynolds, Kyle L Hoedebecke. Stress fractures:Etiology, Epidemiology, Diagnosis, Treatment and Prevention. J Spec Oper Med, Summer 2017, 17(2), 120-130.
8. Lt Col SC Singh, Lt Col A Banerjee. Stress Fractures: Effect Of Prior Physical Activity, Sports Participation And Military Training. MJAFI. Vol 56. No. I. 2000.

9. Abhinav Bhatnagar, Manoj Kumar, Deepak Shivanna, Aski Bahubali, Dayanand Manjunath. High Incidence of Stress Fractures in Military Cadets During Training: A Point of Concern. Journal of Clinical and Diagnostic Research. 2015 Aug, Vol-9(8): RC01-RC03. DOI: 10.7860/JCDR/2015/125 35.6282.

10. Daniel K Ostlie, Fargo ND; Stephen M Simons, Tarsal Navicular Stress Fracture in a Young Athlete:Case Report With Clinical, Radiologic, and Pathophysiologic Correlations. J Am Board Fam Pract 14 (5) : 381 - 385 ,2001.

11. Stuart J. Warden, Irene S. Davis, - Michael Fredericson. Management andPrevention of Bone Stress Injuries in Long-Distance Runners. Journal of orthopaedic \& sports physical therapy | volume 44 | number 10 | October 2014

12. Deepak S. Patel, Matt Roth, Neha Kapil, Stress Fractures: Diagnosis, Treatment, and Prevention. American Family Physician. Volume 83, Number 1, January $1,2011$.

13. Ekenman I; Milgrom C; Finestone A; Begin M; Olin C; Arndt T; Burr D, The role of biomechanical shoe orthoses in tibial stress fracture prevention. Am J Sports Med 2002 Nov - Dec; 30 (6): 866 - 70.

14. Gillespie WJ; Grant I, Interventions for preventing and treating stress fractures and stress reactions of bone of the lower limbs in young adults . Cochrane Database Syst Rev 2000 ; (2) : Cd000450

15. Karl B. Fields, Jeannie C. Sykes, Katherine M. Walker, and Jonathan C. Jackson. Prevention of Running Injuries. Current Sports Medicine Reports. Volume 9 c Number 3 c May/June 2010.

16. Graeme L. Close, Craig Sale, Keith Baar, Stephane Bermon. Nutrition for the Prevention and Treatment of Injuries in Track and Field Athletes. International Journal of Sport Nutrition and Exercise Metabolism, 2019, 29, 189-197. https://doi.org/10.1123/ijsnem.2018-0290.

17. Thein E, Mahlouly J. Stress fractures. Rev Med Suisse. 2019 Dec 11;15(675):2293-2297. [Article in French; Abstract available in French from the publisher]. 